\section{Recurrent deep vein thrombosis presenting in a patient with overt hyperthyroidism}

\author{
Pramila Dharmshaktu, Abhilasha Garg, \\ Dinesh Dhanwal, Naresh Gupta \\ Department of Medicine, Maulana Azad \\ Medical College, New Delhi, India
}

\section{Abstract}

We present a 35 -year-old male patient who was diagnosed with hyperthyroidism and admitted to our hospital with complaints of pain and swelling over his left lower limb. Physical examination was suggestive of deep vein thrombosis of left lower limb. On further investigations and work up, he was found to have deep vein thrombosis of left lower limb involving left common femoral, popliteal and external iliac vein. Inherited causes of hypercoagulable states were ruled out after investigations. Serum homocystein levels were normal and serum antinuclear antibodies was negative. Factor VIII levels were raised. Two months later patient again presented with deep vein thrombosis of right lower limb. Factor VIII levels were out of range this time. Hyperthyroidism has been associated with hypercoagulability by various mechanisms but whether it is a true hypercoagulable state is not yet proven and reported in only few case reports.

\section{Introduction}

The link between the hemostatic system and thyroid diseases has been investigated about a century ago. Both subclinical as well as overt hyperthyroidism is found to be associated with coagulation abnormalities. Globally, these disorders involve both primary and secondary hemostasis and range from subclinical subtle laboratory abnormalities to life-threatening hemorrhages or thrombotic events rarely. While overt hypothyroidism is found to be associated with a bleeding tendency, hyperthyroidism has emerged to have an increased risk of thrombotic events also. However whether hyperthyroidism is a true risk factor for hypercoagulable state is not yet well proven and it is also not done in the thrombophilia workup. Hyperthyroidism is associated with increased levels of factor VII and vWF. These complications are rare and was demonstrated in case reports only.

\section{Case Report}

A 35-year-old male patient was admitted to our hospital in the month of march 2012. Patient was a known case of hyperthyroidism for past 2 years and on oral carbimazole $15 \mathrm{mg}$ twice daily. Patient was having symptoms of thyrotoxicosis for past 4 years but diagnosed only 2 years back. For past 6 month he was also having pain in right loin region. Pain was recurrent, colicky in character and associated with radiation to left thigh and testicles. It used to get relieved on taking medicines prescribed by some local practitioner. It was only 2 months back when his pain became severe, incapacitating and he visited to our surgery OPD where on X ray KUB he was found to have small concretions in right kidney. Since then he was on oral NSAID'S. This time patient presented to us with the complaints of swelling, pain and tenderness in left lower limb which used to increase during walking and increase in the intensity of loin pain associated with decreased urinary stream. On examination tenderness was present over right renal angle without any renal bruit. Local examination of lower limb revealed tender swollen and erythematous left lower limb. Homan's and Moses sign for DVT were positive. Complete blood counts revealed Hb $12.5 \mathrm{gm} / \mathrm{dL}$, TLC 9120 cells per cu mm, platelet counts 2.31 lac per cu mm. Kidney function test revealed serum urea of 34 $\mathrm{mg} / \mathrm{dL}$ and creatinine of $0.6 \mathrm{mg} / \mathrm{dL}$. Ultrasound Doppler for lower limb venous system revealed thrombosis of left popliteal, superficial femoral, common femoral and proximal external iliac vein. Ultrasound abdomen demonstrated bilateral normal size kidney with multiple renal concretions in upper pole of right kidney. Further investigations revealed serum calcium $8.9 \mathrm{mg} / \mathrm{dL}$, serum phosphorus $2.2 \mathrm{mg} / \mathrm{dL}$, serum ALP $157 \mathrm{mg} / \mathrm{dL}$. Other investigations for DVT revealed serum prothrombin time (PT) 17.04 seconds with control of 14 seconds, activated plasma thromboplastin time (aPTT) 29.6 seconds with control of 29.6 seconds, international normalized ratio (INR) 1.40. D-dimer came out to be positive. Serum fibrinogen levels were high at $703.5 \mathrm{mg} / \mathrm{dL}$. Serum homocystein and serum ANA were normal. Other genetic causes of hypercoagulable states as protein C, S deficiency, factor $\mathrm{V}$ leiden mutation were ruled out. Thyroid function test revealed free T3 (FT3) 7.43 pg/mL (normal range 2.0-4.4 $\mathrm{pg} / \mathrm{mL}$ ), free T4 (FT4) $4.10 \mathrm{ng} / \mathrm{dL}$ (normal range $0.93-1.7 \mathrm{ng} / \mathrm{dL}$ ), TSH $0.005 \mathrm{micro} \mathrm{IU} / \mathrm{mL}$ (normal range $0.93-4.3$ micro $\mathrm{IU} / \mathrm{mL}$ ). Factor VII levels were high at $174 \%$ with normal range of $50-150 \%$. Based on these investigations patient was started low molecular weight heparin at dose of $60 \mathrm{mg}$ subcutaneous twice daily 12 hours apart and oral warfarin at initial dose of $3 \mathrm{mg}$. Dose of oral carbimazole was also
Correspondence: Pramila Dharmshaktu, A-404, Crown Apartments, Sector 7, Dwarka, Plot 18-B, New Delhi, India.

Tel. +91.958.293.4837.

E-mail: dr.pramila09@gmail.com

Key words: hyperthyroidism, deep vein thrombosis.

Acknowledgements: we would like to thank our patient for his cooperation and wish for his good health.

Contributions: PD is the treating resident and mainly responsible for drafting and in conception of the case report; AG helped in working up the patient; DD, NG, has given the ultimate guidance regarding the management of the patient and guided me in making of this case report.

Conflict of interests: the authors declare no potential conflict of interests.

Received for publication: 2 October 2013. Accepted for publication: 11 November 2013.

This work is licensed under a Creative Commons Attribution NonCommercial 3.0 License (CC BYNC 3.0)

(O) Copyright P. Dharmshaktu et al., 2014 Licensee PAGEPress, Italy

Endocrinology Studies 2014; 4:5096

doi:10.4081/es.2014.5096

increased to $30 \mathrm{mg}$ thrice daily. Patient improved symptomatically and swelling also reduced with time. Patient was on maintenance oral warfarin therapy and following in opd. Two months later again he presented in the emergency with swelling, pain and tenderness of right lower limb. On further history patient revealed noncompliance with his medicines. Examination was suggestive of right lower limb DVT. USG Doppler was also suggestive of DVT right lower limb. Patient was restarted on tablet warfarin $5 \mathrm{mg}$ daily and tablet carbimazole $20 \mathrm{mg}$ thrice daily. Factor VIII essay was also repeated and found to be out of range. (high values).

Patient is now under adequate dose of carbimazole and compliant to his medicines. On further follow up he did not show such episodes, swelling has also subsided significantly. Repeat factor VIII levels were normal at $142 \%$.

\section{Discussion}

Hyperthyroidism when untreated or inadequately treated leads to various complications of body systems. Hyperthyroidism, per se is 
also a risk factor for development of many diseases. Arterial or venous thrombosis is one of the rare complications where hyperthyroidism is implicated as a risk factor.

Hyperthyroidism is not a widely recognized association with venous thromboembolism (VTE) and thyroid function test is certainly not a routine test in thrombophilia screening. ${ }^{1-3}$ However, various changes in the coagulation pathway and platelet function that can predispose to VTE have been described in patients of hyperthyroidism. In particular, a number of case reports have documented acute venous thrombosis complications in patients with overt hyperthyroidism. ${ }^{4}$ Verberne et al. ${ }^{5}$ reported a case of a young woman with severe thyrotoxicosis and concurrent cerebral venous sinus thrombosis. A possible cause for this is persistent elevation of factor VIII levels which has been shown to be independently associated with both first and recurrent venous thrombosis. ${ }^{6,7}$ So the most biologically plausible mechanism for a causal link between hyperthyroidism and VTE is related to significant but reversible elevation of factor VIII. An indirect effect of hyperthyroidism via the betaadrenergic receptors is also a possible thepory. ${ }^{8}$

Stuijver et al. ${ }^{9}$ found that thyrotoxicosis shifts the haemostatic balance towards a hypercoagulable and hypofibrinolytic state with a rise in factors VIII and IX, fibrinogen, von Willebrand factor, and plasminogen activator inhibitor-1. This was observed in endogenous and exogenous thyrotoxicosis, and in subclinical as well as overt hyperthyroidism. Studies have documented sustained but transient elevation of factor VIII and von
Willebrand factor (vWF) activity in patients with overt hyperthyroidism. The elevation in factor VIII and vWF resolved over few weeks of treatment suggesting a direct role of hyperthyroidism in elevation of factor VIII and vWF activity. 10

Erem et al. ${ }^{8}$ showed statistically significant elevations in vWF, factor IX, antithrombin III, fibrinogen, and plasminogen activator inhibitor-1 (PAI-1) levels, and reduction in factor $\mathrm{X}$ and tissue plasminogen activator (tPA) levels in hyperthyroid subjects when compared to their euthyroid controls. vWF, PAI-1, and tPA are among the important endothelium derived proteins, and hence they suggested that hyperthyroid patients may experience vascular endothelial dysfunction with decreased fibrinolytic activity in the blood. Burggraaf et al. ${ }^{10}$ similarly showed that hyperthyroid patients with Grave's disease had significantly altered levels of endothelium-associated proteins, and these changes were corrected after patients became euthyroid with therapy. There is paucity of literature describing the incidence of VTE in patients with thyrotoxicosis.

\section{References}

1. Maes J, Michotte M, Velkeniers B, et al. Hyperthyroidism with increased factor VIII procoagulant protein as a predisposing factor for cerebral venous thrombosis. $\mathrm{J}$ Neurol Neurosurg Psychiatry 2002;73:4569.

2. Squizzato A, Romualdi E, Buller HR,
Gerdes VE. Clinical review: thyroid dysfunction and effects on coagulation and fibrinolysis: a systematic review. J Clin Endocrinol Metab 2007;92:2415-20.

3. Rogers JS, Shane SR, Jencks FS. Factor VIII activity and thyroid function. Ann Intern Med 1982;97:713-6.

4. Franchini M, Lippi G, et al. Hyperthyroidism and venous thrombosis: a casual or causal association? A systematic literature review. Clin Appl Thromb Hemost 2011;17:387-92.

5. Verberne HJ, Fliers E, Prummel MF, et al. Thyrotoxicosis as a predisposing factor for cerebral venous thrombosis. Thyroid 2000;10:607-10.

6. Koster T, Blann AD, Briet E, et al. Role of clotting factor VIII in effect of von Willebrand factor on occurrence of deepvein thrombosis. Lancet 1995;345:152-5.

7. Kyrle PA, Minar E, Hirschl M, et at. High plasma levels of Factor VIII and the risk of recurrent venous thromboembolism. N Eng J Med 2000;343:457-62.

8. Erem C, Ersoz HO, Karti SS, et al. Blood coagulation and fibrinolysis in patients with hyperthyroidism. J Endocrinol Invest 2002;25:345-50.

9. Stuijver DJ, Van Zaane B, Romauldi E. The effect of hyperthyroidism on procoagulant, anticoagulant and fibrinolytic factors: a systematic review and meta-analysis. Thromb Homeostasis 2012;108:1077-88.

10. Burggraaf J, Lalezari S, Emeis JJ, et al. Endothelial function in patients with hyperthyroidism before and after treatment with propranolol and thiamazol. Thyroid 2001;11:153-60. 